\title{
Primary Shipping Designee
}

National Cancer Institute

\section{Source}

National Cancer Institute. Primary Shipping Designee. NCI Thesaurus. Code C51848.

The principal person of contact who denotes where and to whom pharmaceuticals are to be shipped. The person of contact is assigned by the principal investigator and registered with the NCI CTEP Pharmaceutical Management Branch (PMB) as with a distributor of (investigational new drugs (INDs) for all $\mathrm{NCl}$-sponsored trials. In addition, this person is authorized to place orders for investigational agents with PMB, requests drug transfers, and maintains drug inventory documentation at the clinical site. Investigational agents are shipped from the PMB directly to the institution or the investigator's practice site where the agent will be prepared and administered. 